$10-2015$

\title{
Changing Principals' Leadership through Feedback and Coaching
}

Peter Goff

Ellen Goldring

J Edward Guthrie

Leonard Bickman

Follow this and additional works at: https://repository.upenn.edu/cpre_policybriefs

Part of the Curriculum and Instruction Commons, and the Educational Assessment, Evaluation, and Research Commons

\section{Recommended Citation}

Goff, Peter; Goldring, Ellen; Guthrie, J Edward; and Bickman, Leonard. (2015). Changing Principals' Leadership through Feedback and Coaching. CPRE Policy Briefs.

Retrieved from https://repository.upenn.edu/cpre_policybriefs/45

View on the CPRE website.

This paper is posted at ScholarlyCommons. https://repository.upenn.edu/cpre_policybriefs/45

For more information, please contact repository@pobox.upenn.edu. 


\title{
Changing Principals' Leadership through Feedback and Coaching
}

\author{
Abstract \\ Researchers Leonard Bickman, Ellen Goldring, Peter Goff, and J. Edward Guthrie conducted a randomized \\ experiment of principals in a large urban school district to explore if coaching, when combined with \\ feedback from teachers, changes principals' leadership practices. This brief summarizes the research \\ findings regarding the impact of the feedback and coaching intervention on principals' leadership \\ behaviors. \\ Disciplines \\ Curriculum and Instruction | Educational Assessment, Evaluation, and Research \\ Comments \\ View on the CPRE website.
}




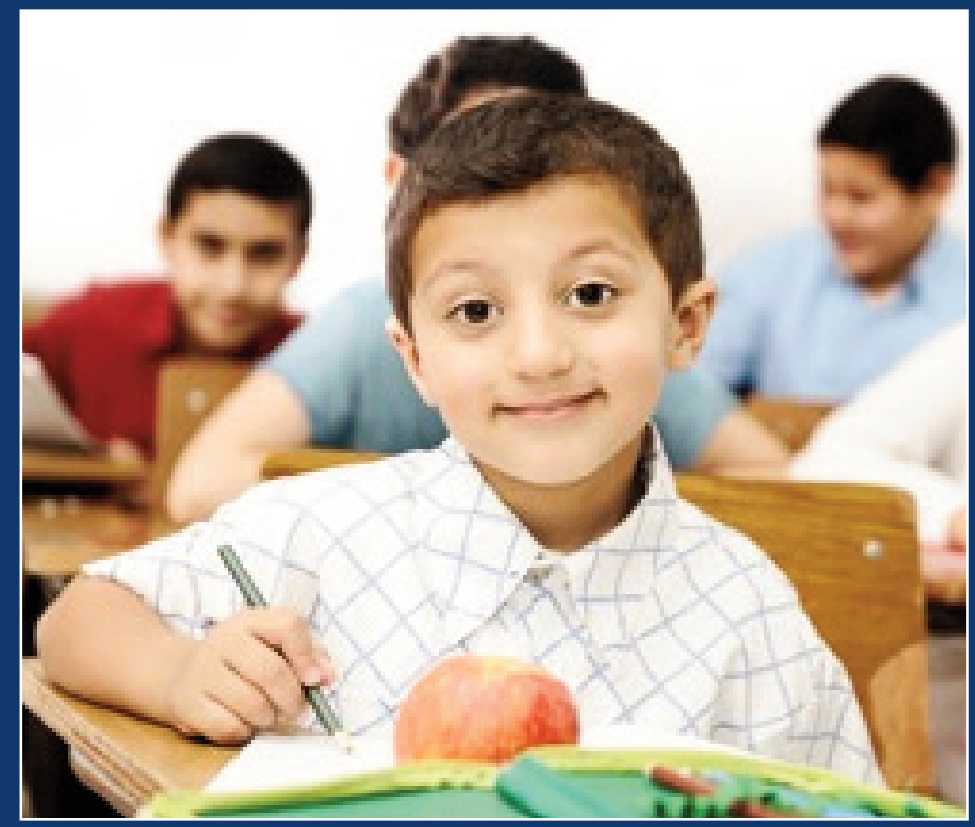

CHANGING CLASSROOM PRACTICE:

The Evaluation of the

School Network Learning Project in Jordan

Presented by

Jaunelle Pratt-Williams

Senior Research Assistant

Thomas Corcoran

Director

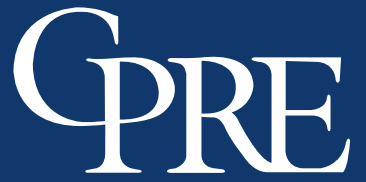


Opinions expressed in this report are those of the authors and do not necessarily reflect the views of USAID, the Queen Rania Teacher Academy, Jordanian Ministry of Education, Jordanian Ministry of Planning, Columbia University Middle East Research Center, the Columbia Global Centers, CPRE Teachers College, or the participating schools. 


\section{TABLE OF CONTENTS}

EXECUTIVE SUMMARY 2

OVERVIEW OF SCHOOL NETWORK LEARNING PROJECT 6

$\begin{array}{ll}\text { Goals of the School Network Learning } & 7\end{array}$

EVALUATING THE PROJECT 9

$\begin{array}{ll}\text { Data Sources and Methods } & 10\end{array}$

THE SCHOOL NETWORK FRAMEWORK 11

$\begin{array}{ll}\text { Participation and Attrition } & 13\end{array}$

Modifications and Adaptations to Professional Development 16

FINDINGS FROM CPRE'S THREE FOCUS AREAS 18

Change: The Reflective Classroom Initiative 18

Self-reported Changes and Challenges from Surveys 22

Similar Findings from Cohort 1 and Cohort 2

Building Capacity within QRTA 27

$\begin{array}{ll}\text { Sustainability } & \mathbf{3 1}\end{array}$

LESSONS LEARNED 33

$\begin{array}{ll}\text { CONCLUSION } & 35\end{array}$ 


\section{EXECUTIVE SUMMARY}

\section{Overview of School Network Learning Project}

In 2007, the Columbia University Middle East Research Center (CUMERC), with the support and patronage of Her Majesty Queen Rania Al Abdullah, facilitated the founding of the Queen Rania Teacher Academy (QRTA) to help advance education in Jordan and throughout the Middle East. Through CUMERC, QRTA and Teachers College, Columbia University (TC) formed a new partnership whose goal was to use high quality in-service training to improve the quality of the public schools in Jordan. The Consortium for Policy in Education at TC (CPRE) took on this work and began collaborating with QRTA to engage current educators in the adoption and use of evidence-based instructional practices in Jordan's elementary and secondary schools. This initiative became known as the School Networks Learning Project and supported networks of schools in different regions of the country as vehicles for providing professional development of teachers in English, mathematics, and science as well as leadership training for principals and education supervisors to support the desired changes in classroom practice.

Five core practices were emphasized during the professional development with the goal being that teachers would focus on these practices and take them back to their classrooms. Schools and teachers made a 2 to 3 year commitment to the project. At the time of the writing of this report, three cohorts have completed the Project and two additional cohorts have begun the Project. Across the three completed cohorts, 2,158 teachers, 894 school leaders, and 104 other educators participated in the School Network Project, totaling 3,130 participants over the almost six years of the Project's implementation. 


\section{Purpose of the Report}

This report is the second evaluation report on the Project and focuses on change over time in classroom practice, transfer of capacity, and sustainability. The research questions, below, were central to each of these concepts and guided the evaluation.

Change in practice: To what extent has the program resulted in changes in teachers' and administrators' values, dispositions, and practices? (The focus is particularly on the third cohort for this question.)

Transfer of capacity: To what extent has QRTA developed the capacity to lead, support, and develop instructional improvement efforts?

Sustainability: How and to what extent have the schools been able and willing to sustain their instructional improvement efforts? What obstacles have they encountered in their efforts to implement and sustain the new practices?

Multiple sources of data were used to explore theses questions with much of the findings in the report coming from the analysis of participant surveys and video observations of a sample of Cohort 3 teachers. 


\section{Key Findings}

\section{Change in practice}

Videotaping of classroom observations was used to measure change in practice by participant teachers over time.

- There was positive change among the participants on over $80 \%$ of the measured indicators.

- The greatest change occurred in classroom environment and lesson development.

- Female participants demonstrated greater changes than their male peers but it is important to note that the majority of the participants were women.

Content knowledge remained a growth area for the majority of the participants, in Cohort 3 as reported by teacher and school leader participant surveys and analysis of the videos.

Participant surveys also indicated positive change in practices both among teachers and school leaders.

- The majority of teachers in Cohort 3, across the networks, reported changes in how often they used student collaboration and engagement in the classroom.

- Teachers reported an increase in how often they encouraged student discussion in class.

- More than $80 \%$ of the math and English writing teachers reported increases in their use of mixed groups or pairs; the same for over 70\% of science teachers.

- School leaders reported observing teachers more often.

- School leaders noticed positive changes in the types of questions teachers asked in the classroom noting that they were higher level questions and that they probed for student understanding.

Challenges still remain for both teachers and school leaders that will need to be addressed in the future.

- While teachers are able to collaborate more often, the amount time spent in these meetings is still limited.

- The majority of teachers and school leaders reported concerns about teachers' content knowledge and their confidence in their understanding of the content. 


\section{Transfer of capacity}

Overall, collaboration between the CPRE team and QRTA team members led to a successful transfer of knowledge and skill to QRTA staff.

- Participants' reports indicated that the workshops' organization, content presented, and usefulness remained consistent, on average, across all three cohorts as the transfer to QRTA took place.

- The number of QRTA staff contributing to the Project has almost tripled growing from only 9 team members in 2009 to 25 team members in 2014.

\section{Sustainability}

While not perfect, systems are in place to build the capacity of the network communities to sustain both the Project and the learning communities that develop from the program.

- After the first year of the project, on-site support at schools was provided somewhat unevenly by QRTA.

- QRTA staff believe on-site support is important and are making efforts to meet participants needs.

- The majority of the teacher networks in Cohort 2 and Cohort 3 held the four required network meeting with many holding additional meetings.

\section{Conclusions}

Overall, the School Network Project has had a positive impact on both educators and the staff at the Queen Rania Teacher Academy. Continuing to engage the program participants and supporting them in their schools is an on-going effort. QRTA has acknowledged the challenges that the partnership faced during the first five years of implementation and is exploring ways to improve the program. Adapting to the needs of the participants has been a critical part of the program and continuing to assess their needs and how to meet them will continue to be a key component of the program's success. 


\section{OVERVIEW OF SCHOOL NETWORK PROJECT}

In 2007, the Columbia University Middle East Research Center (CUMERC), with the support and patronage of Her Majesty Queen Rania Al Abdullah, facilitated the founding of the Queen Rania Teacher Academy (QRTA) to help advance education in Jordan and throughout the Middle East. Through CUMERC, the newly created Queen Rania Teacher Academy (QRTA) and Teachers College, Columbia University (TC) formed a new partnership. The goal of this partnership was to improve the quality of the public education system through the provision of high quality in-service training for current teachers. The Consortium for Policy in Education at TC (CPRE) took on this work and began collaborating with QRTA. Funded by the Jordan Ministry of Planning and United States Agency for International Development (USAID), and supported by the Ministry of Education (MOE), the partnership developed a model of high quality professional development that was scalable within Jordan. It supports the adoption and use of evidence-based instructional practices in Jordan's elementary and secondary schools. This initiative became known as the School Networks Learning Project, also referred to as "the Project" or "the program." The Project created and supported networks of schools in different regions of the country as vehicles for providing professional development for teams of teachers in English, mathematics, and science as well as leadership training for principals and education supervisors to support the desired changes in classroom practice. Each network focused on improving instruction in one of the three content areas: English, mathematics, or science. The first cohort of participants started the Project in 2009 with four additional cohorts beginning in the subsequent years. 


\section{Goals of the School Network Learning Project}

The plan for instructional improvement was guided by research about (1) comprehensive approaches to school improvement, (2) effective professional development practices, and (3) effective instructional practices. The professional development workshops led by skilled trainers formed the foundation of the project. The plan was to provide nine events over three years to develop momentum for the changes and sustain the engagement to support implementation. The design and the delivery of the professional development were guided by evidence that effective programs include opportunities for active, hands-on learning, provide sustained and intensive support to deepen learning and use of the new strategies and content, utilize experienced practitioners as trainers, show respect for teacher knowledge and experience, and allow time for reflection and feedback from participants. The focus and content of the professional development were guided by substantive research that has identified some of the most effective instructional practices and strategies while incorporating the needs of the educators in the program. 
Five core practices were emphasized during the professional development with the goal being that teachers would focus on these practices and take them back to their classrooms. The core practices, which are often referred to at the "big effects" or "high-leverage" practices in the workshop context, are:

1) Lesson design: connecting the lesson to important concepts or skills (standards), selecting appropriate tasks, opening the lesson and reviewing prior knowledge, engaging students, making learning goals explicit, providing time for students to explore the content and apply it, and closing the lesson with review and summary;

2) Team-based instruction: using various forms of peer and group learning or teaming with careful attention given to how class size, group composition and roles, seating arrangements, group stability, the number of groups, and other factors influence the effectiveness of this approach;

3) Academically focused and rigorous tasks: Lessons should be built around tasks that are intellectually challenging (that is, have high cognitive demand), but also be achievable by all or almost all of the students in the class. Lessons that require students to communicate their understanding of the concepts and to explain the connections among concepts or to apply concepts to new problems have higher cognitive demand than lessons that ask students to memorize material or follow procedures or algorithms;

4) Formative assessment/adaptive instruction: process of using data (observations, questioning, conferencing, quizzes, etc.) about student learning to adapt instruction to more effectively support student learning; and

5) Student-centered discussion: student discourse in the classrooms that allows the teacher to understand their students' academic thinking, and that allows students to develop greater understanding.

Later in the project, a sixth practice, frequent writing in-class or out-of-class, was added to this list of high-leverage practices.

Work at the schools-network meetings and school site visits—was intended to support teachers and leaders as they implemented the new practices, and to foster communities of practice that, once established, could sustain and extend the instructional improvement initiatives teachers and leaders were undertaking. Additionally, the hope was that these communities could cultivate a mutually reinforcing ethos of continuous instructional improvement within the school communities and within the content-area networks of schools. 


\section{EVALUATING THE PROJECT}

This report is the second evaluation report in the second phase of the Project's evaluation. For the first phase evaluation and report ${ }^{1}$ a descriptive and formative evaluation approach was taken. In the second phase CPRE's researchers shifted to an approach that attempts to measure change over time. Specifically, the research focused on three concepts: change, transfer, and sustainability. The following questions guided this phase of the evaluation:

1) Change: To what extent has the program resulted in changes in teachers' and administrators' values, dispositions, and practices? (The focus is particularly on the third cohort for this question.)

2) Transfer: To what extent has QRTA developed the capacity to lead, support, and develop instructional improvement efforts?

a. How has their role developed, and what is the quality of the support that they have been provided by the project?

b. How effective have the mechanisms for transferring leadership of the work to QRTA been?

c. How does the quality of the Jordanian work compare to the work done by the CPRE teams?

3) Sustainability: How and to what extent have the schools been able and willing to sustain their instructional improvement efforts? What obstacles have they encountered in their efforts to implement and sustain the new practices?

1 Copies of "Growing School Networks for Instructional Improvement in Jordan, 2009-2012" and "Jordan School Learning Networks Project Interim Report, April 2013" can be found at http://www.cpre.org/jordan-report 
A substantial part of the documentation work in this second phase concentrated on gathering data to establish a baseline understanding of program participants' instructional practice. This was done through collecting a sample of videos of classroom instruction from the third cohort of teachers at the beginning of their participation in the program and through a baseline survey designed to measure participants' initial attitudes and dispositions, values, and reported practices related to the big effects practices that have been at the core of the training. Subsequently, the research team collected the same types of measures toward the end of the program. These data allowed CPRE to estimate the extent to which the Project has effected change, particularly in the instructional core. In the subsequent sections, the findings are presented giving emphasis to Cohort 3 since they were a part of the major transitioning of the program during which more of the Project was led by QRTA staff.

\section{Data Sources and Methods}

This report relies on the following sources of data:

- Participation records maintained by QRTA regarding attendance of teachers, principals, supervisors, and others at Project meetings and workshops;

- Questionnaires from CPRE and QRTA trainers regarding their roles in implementing the project and perceptions of the transition of the leadership of the Project to the Jordanian counterparts;

- Surveys of participants

- Administrative records maintained by QRTA on the internal growth in staff members to support the Program; and

- Videos collected from a sample of Cohort 3 teachers at the start of the Program and toward the end. 


\section{THE SCHOOL NETWORK FRAMEWORK}

The School Learning Networks Project centers on creating a culture of continuous improvement in schools by providing long-term professional development support for teachers and principals through focused workshops, meetings with teachers across network schools, and school-site support for teachers. Through the Project, participating teachers attended a series of intensive, content-specific two-to-threeday workshops over the course of a few years. They also attended Network meetings, conducted at schools, designed to allow participants to learn from each other and share their successes and challenges in implementing some of the instructional strategies introduced during workshops. Table 1 (on page 12) lists the number of times that the various cohorts of educators had the opportunity to participate in workshops or meetings and the percentage of those invited who chose to attend. Project staff also visited participating schools to support use and refinement of workshop strategies through structured classroom observations, feedback and discussions with teacher teams. School principals and supervisors received training that provided them with tools and strategies to support and reinforce the instructional improvement efforts within their schools and to provide feedback to teachers as they implemented these new strategies. This training complemented the teacher professional development. The number of workshops varied both across cohorts and networks due to scheduling difficulties, but, on average, each group of participants had at least 7 workshop opportunities. 
Table 1. Cohort Attendance for Project Activities: February 2011- September 2014

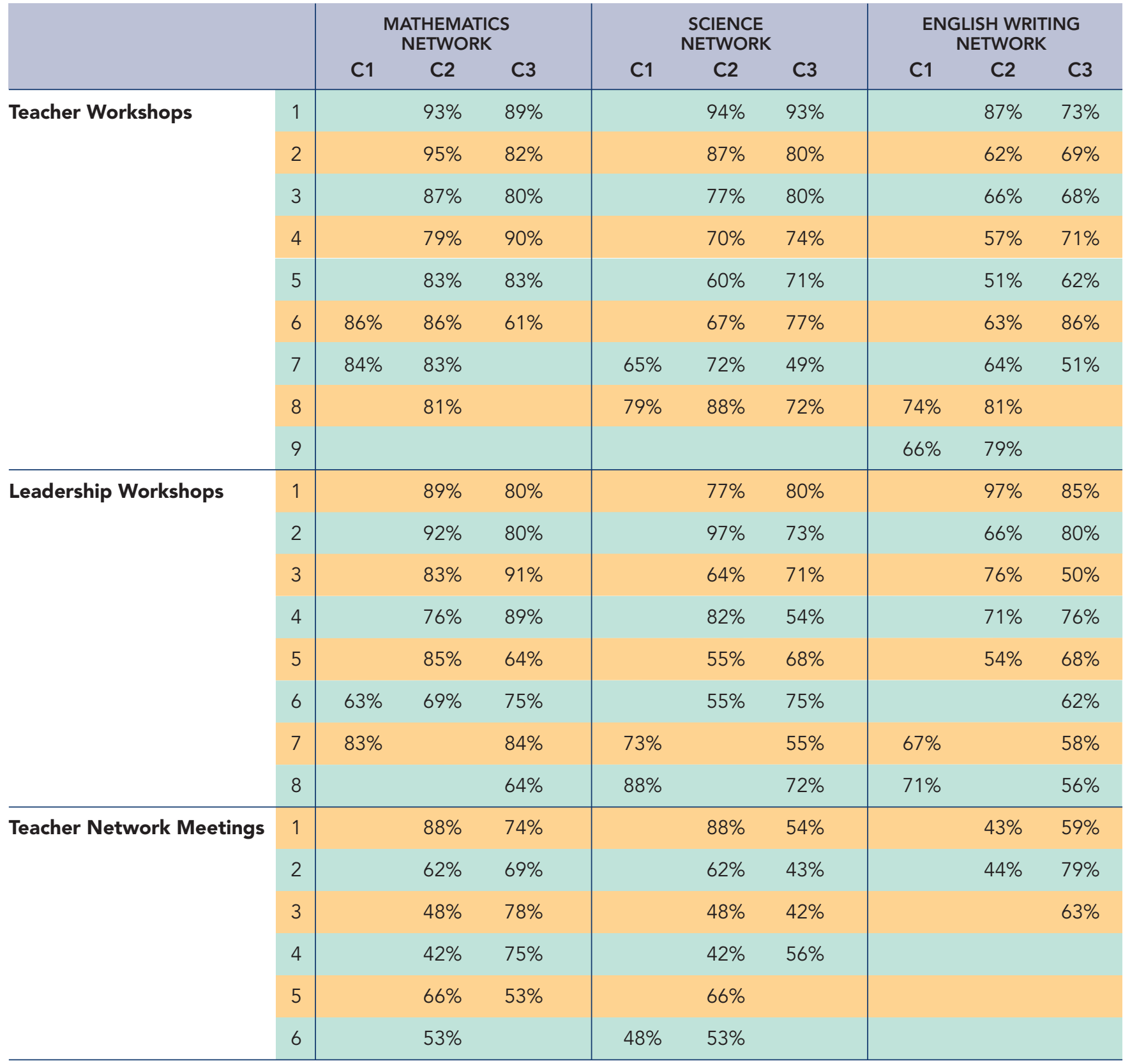

Source: QRTA Workshop records

Blank cells indicate workshop did not take place during the time period. 


\section{Participation and Attrition}

Table 2. Program Participation Rates by Cohort

\begin{tabular}{|c|c|c|c|c|c|c|c|c|}
\hline & & & SCHOOLS & TEACHERS & PRINCIPALS & SUPERVISORS & OTHERS* & TOTAL \\
\hline \multirow[t]{6}{*}{ Mathematics } & Cohort 1 & Initial Participants & 24 & 126 & 34 & 17 & 12 & 189 \\
\hline & & Attrition & $0 \%$ & $12 \%$ & $26 \%$ & $6 \%$ & $0 \%$ & $13 \%$ \\
\hline & Cohort 2 & Initial Participants & 25 & 142 & 31 & 26 & 4 & 203 \\
\hline & & Attrition & $0 \%$ & $7 \%$ & $16 \%$ & $8 \%$ & $50 \%$ & $9 \%$ \\
\hline & Cohort 3 & Initial Participants & 28 & 144 & 38 & 18 & 1 & 201 \\
\hline & & Attrition & $4 \%$ & $22 \%$ & $26 \%$ & $28 \%$ & $0 \%$ & $23 \%$ \\
\hline \multirow[t]{6}{*}{ Science } & Cohort 1 & Initial Participants & 0 & 109 & 28 & 18 & 14 & 169 \\
\hline & & Attrition & $0 \%$ & $17 \%$ & $36 \%$ & $11 \%$ & $0 \%$ & $18 \%$ \\
\hline & Cohort 2 & Initial Participants & 0 & 116 & 35 & 29 & 1 & 181 \\
\hline & & Attrition & $0 \%$ & $18 \%$ & $11 \%$ & $14 \%$ & $0 \%$ & $16 \%$ \\
\hline & Cohort 3 & Initial Participants & 30 & 120 & 34 & 12 & 4 & 170 \\
\hline & & Attrition & $0 \%$ & $24 \%$ & $9 \%$ & $33 \%$ & $0 \%$ & $21 \%$ \\
\hline \multirow[t]{6}{*}{ English Writing } & Cohort 1 & Initial Participants & 0 & 135 & 32 & 27 & 2 & 196 \\
\hline & & Attrition & $0 \%$ & $30 \%$ & $31 \%$ & $22 \%$ & $0 \%$ & $29 \%$ \\
\hline & Cohort 2 & Initial Participants & 0 & 131 & 36 & 2 & 0 & 169 \\
\hline & & Attrition & $0 \%$ & $45 \%$ & $25 \%$ & $50 \%$ & $0 \%$ & $41 \%$ \\
\hline & Cohort 3 & Initial Participants & 0 & 112 & 50 & 10 & 2 & 174 \\
\hline & & Attrition & $0 \%$ & $29 \%$ & $24 \%$ & $59 \%$ & $50 \%$ & $29 \%$ \\
\hline
\end{tabular}

* "Others" includes Ministry of Education officials, CADER staff, winners of the Queen Rania Al Abdullah Award for Distinguished Teacher, and members of the design team. Source: QRTA workshop record 
Across the three cohorts and subject networks, 2,158 teachers, 894 school leaders, and 104 other educators participated in the School Network Project, totaling 3,130 participants over the almost 6 years of the Project's implementation. A breakdown of the number of initial participants by Cohort and Network as well as the percentage of participants who left the program can be found in Table 2 (on page 13).

Each cohort targeted educators from different regions of Jordan (See Table 3 below). The educators in Cohort 1 were from Amman, which is also where QRTA's headquarters are located. The networks for Cohort 2 were from governorates, or provinces, in the southern region of Jordan. Some of the schools were more than a two hour drive from Amman making it difficult for participants to come to QRTA, so the workshop teams often held the professional development sessions at network schools. The Cohort 3 governorates were slightly closer to Amman as they were in the Northern region of Jordan, but still quite a distance from Amman. Again, workshop leaders transferred much of the professional development to schools within the networks.

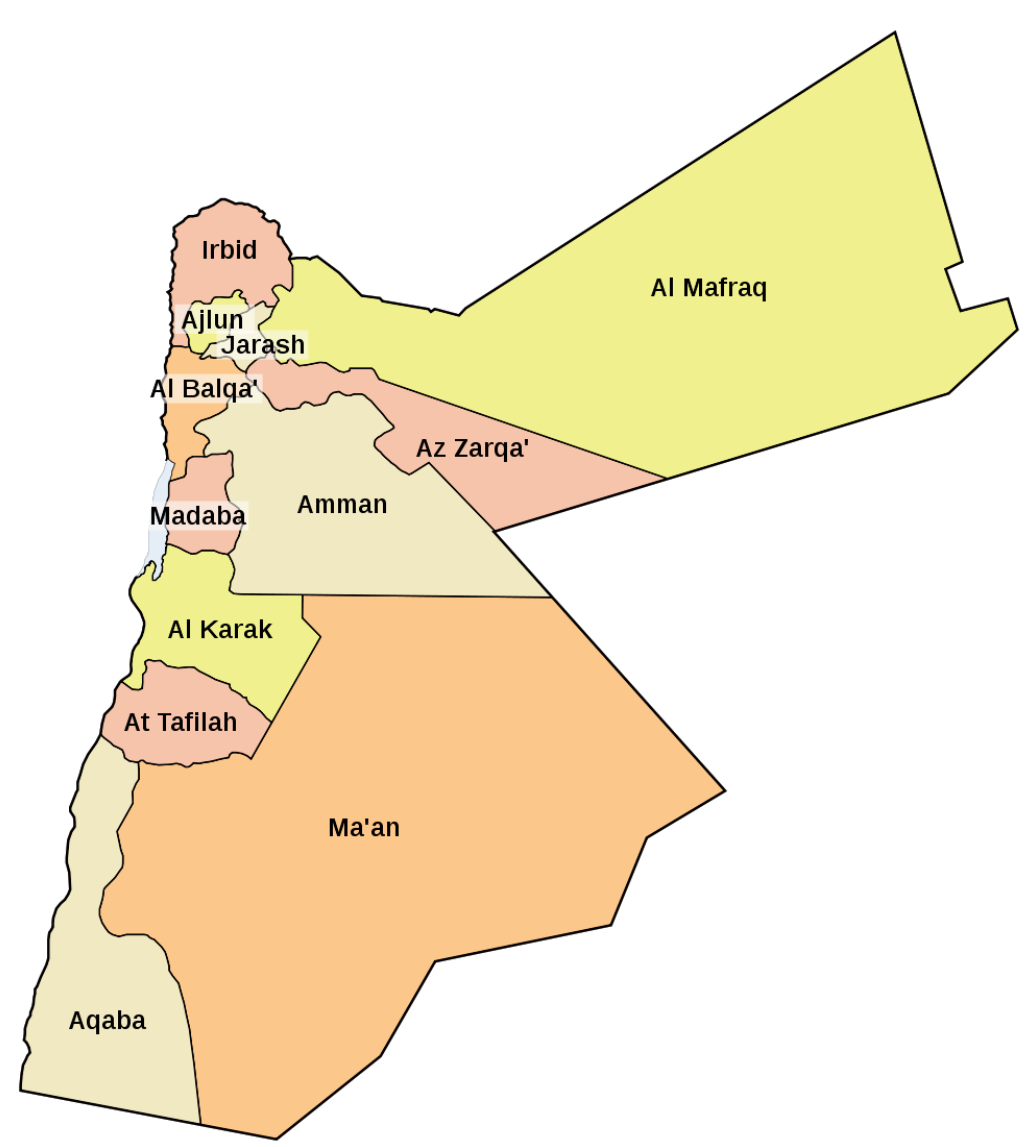

Table 3. Cohort Locations by Governorates (Provinces)

\begin{tabular}{lll} 
& & GOVERNORATE \\
\hline Cohort 1 & Math & Amman \\
& Science & Amman \\
& English & Amman \\
& Math & Karak; Tafeileh \\
& Science & Karak, Tafeileh \\
& English & Aqaba \\
\hline Cohort 3 & Math & Irbid \\
& Science & Mafraq \\
& English & Jarash; Ajloun \\
\hline
\end{tabular}


Despite the extended and intensive nature of the Project that required participation over three years to complete the program, most teachers and school leaders sustained participation throughout the course of the program. Even as the cohorts grew and the locations of the networks became further from QRTA, the percentage of educators choosing to continue the program remained between $76 \%$ and $80 \%$, on average (see Table 2 on page 13). Participants who missed two or more consecutive workshops were called by QRTA staff and asked if they planned to continue to participate in the program. CPRE counts those who confirmed that they would not continue the program as dropouts. Across the three cohorts, the dropout rates were highest in English writing. These higher attrition rates are likely due to the fact that the official ERfKE curriculum traditionally focuses very little on extended writing. Giving attention to writing through the Project requires taking time away from the ERfKE lessons. The writing workshop model also requires a significant shift in instructional practice that may be uncomfortable for some English writing teachers. Language also may have been a barrier for teachers since the instruction as well as the writing is in English, a second language for most teachers and students.

Attendance rates at individual workshops were also relatively high (see Table 1 on page 12). The attendance rates were calculated as the percentage of invited workshop participants who actually attended the workshop. Workshop attendance rates ranged from $48 \%$ to almost $100 \%$, with an average of $74 \%$ for both leadership and teacher workshops held during this time period. Attendance at the teacher Network meetings was slightly lower with an average of about $68 \%$ of teachers attending the meetings. Not surprisingly, attendance rates tended to be slightly lower at workshops and meetings later in the Program cycle. 


\section{Modifications and Adaptions to Professional Development}

As discussed in the prior documentation reports, CPRE and QRTA trainers made some significant changes following the first year of the professional development program. In year two, the teacher workshops and support for Cohort 2 and the second-year workshops in Cohort 1 were adapted in response to feedback about teachers' needs, schedules, and school contexts, as well as the cultural context. For example, in mathematics and science, content was revised and condensed to allow for the reduction of the workshops from four-day to two-day sessions, in which half of the participants attended one of two two-day sessions to allow for more time for discussion among participants and personalized feedback from workshop leaders. In English writing, trainers modified workshop curriculum materials to better address the variation in students' English-language skills, and adapted the language used in workshop materials to better match the teachers' English-language abilities. Additionally, English writing trainers were able to illustrate the writing process using examples of work by Jordanian students-a new resource that some trainers believe has led to greater buy-in from participants earlier in the professional development cycle. Teacher workshops leaders across all networks adapted their materials to ensure that the instructional strategies and lessons could be used with minimal resources and in large classes. Modifications were also made for leadership workshops. In the second year of the Cohort 1 leadership workshops, in response to limited implementation of workshop strategies inside schools and the perception that the work was not connecting directly enough with practice, workshop leaders began to hold workshop sessions in schools and initiated learning walks in schools with small groups of participating principals. Some of the trainings were also moved to the school site for later cohorts in the second and third years of the training. 
As Cohort 3 schools began the program, the content and focus of the professional development workshops stabilized and remained substantively the same as in Cohort 2. The focus of the work since 2011, which includes the final Cohort 2 trainings and all of the Cohort 3 trainings, was on fine-tuning the workshops, rather than making any significant shifts in their content or organizational design. Reports from CPRE and QRTA trainers suggest that these minor adaptations and adjustments occurred constantly and were part of a continuous improvement process. Trainers relied on feedback from and discussions with teachers during the independent work time in the workshops to determine whether the teaching points of the session were clear to teachers. The training teams met each day after the workshops to review the work, and to make changes required to enhance engagement, understanding, and use.

Based on workshops and school visits from prior cohorts, trainers identified some of the challenges teachers faced in implementing the instructional strategies presented in the workshops. With this information, they developed potential solutions or supports to assist implementation. Feedback from teachers and leaders during on-site support and Network meetings about challenges also informed workshop and on-site support adaptations. English writing trainers used student work that teachers brought to the workshops as evidence that workshops were effective or needed improvement. Feedback from complementary work, particularly the professional development that QRTA staff and CPRE trainers provided in Jerusalem, cross-fertilized with the Jordanian professional development to stimulate further improvements. 


\section{FINDINGS FROM CPRE'S THREE FOCUS AREAS}

\section{Change: The Reflective Classroom Initiative}

The Reflective Classroom Initiative was a smaller effort within the Project that collected and analyzed video observations of teachers in the classroom setting. It began in 2012 with the third cohort of teachers in an effort to capture changes in teacher practices, over time, and to determine if these changes reflected the targeted practices that were presented and emphasized in the professional development workshop sessions. Additionally, the video observations allowed the research team to determine which areas of the program appeared to be most successful and those that were potential growth areas.

The Study. Teachers were filmed in 2012 when they began the Network Project and then, again, in 2014 as they neared the end of the program. On average, the research team recorded 2 lessons for each teacher in 2012 and 2 lessons in 2014. Participation was voluntary and it was made clear to teachers that the focus of the Initiative was to learn more about how the Network Project was influencing participants' classroom practices. While the goal was to measure change over time, the evaluation of teachers was not a part of the analysis. Both the identities of the teachers and students in the videos were kept confidential.

Due to resource constraints, the research team could only videotape a sample of the Cohort 3 teachers. Researchers randomly sampled the Cohort 3 participants first by school and then within subgroups based on the subject the teacher taught and grade level in an effort to ensure the sample represented the program participants. Teachers within the sample were then asked to participate noting that participation was voluntary. Initially, 31 teachers agreed to be videotaped, but only 25 of the original participants completed the Initiative by participating in the videotaped observations in 2014. The Initiative yielded 86 videotaped lessons. Each video was coded by two trained coders, who were also fluent in Arabic. Coders used the Upgrade Observation Protocol ${ }^{2}$, which was adapted by CPRE researchers from the 
UTeach Observation Protocol (UTOP). The instrument can be used to assess the overall quality of classroom instruction in English/writing, math, and science from kindergarten to the undergraduate level. The Upgrade Protocol is composed of 34 indicators across 4 major categories: Classroom Environment, Lesson Structure, Implementation, and Content. Each indicator was rated on a 5-point Likert Scale (1 to 5), with a N/A (Not Applicable) rating option for a few designated items. Most indicators asked the rater to assess the frequency of the practice as well as the quality of the practice. There were also 4 indicators that rated the teacher on the overall quality of each category.

The indicators in each section specifically measured practices that align with the "big effects" practices from the Network Project. The Classroom Environment section assessed the degree to which the classroom environment was conducive to the learning of mathematics, English/writing and science, and how the teacher facilitated and created this setting. The Lesson Structure section assessed the organization of the lesson-opening, work period, and closing-and how well the teacher organized the sequence of learning activities during the class period, and the degree to which this organization facilitated the learning of English/writing, mathematics or science. The Implementation section assessed the instructional decisions, strategies, and practices that the teacher used during the lesson, how well the lesson flowed, and whether the teacher ensured that all students remained engaged in the content being covered. The Content section assessed the quality of the mathematics, English/writing, or science content being constructed by students during the class period. Although there were indicators within the Content section that measured the teacher's content knowledge, it is an important to note that this section was meant to address the quality of the content that students were exposed to during class, both directly communicated by the teacher and learned through other means like discussion and independent practice. 


\section{Chart 1.}

Indicators where Teachers Demonstrated the Most Positive Change On Average

Negative No Change Positive

1.1 Frequency of collegial student group work

\begin{tabular}{|lll}
$33 \%$ & $4 \%$ & $63 \%$ \\
& & \\
\hline $33 \%$ & $4 \%$ & $63 \%$ \\
\hline
\end{tabular}

1.1 Quality of the collegial student work $33 \%$ $25 \%$ $21 \%$ $54 \%$

2.4 Quality of resources used in lesson $25 \%$ $21 \%$ $54 \%$

2.3 Quality of the lesson structure around engagement

\section{$25 \%$} $58 \%$

3.2 Frequency that the teacher involved all students

\begin{tabular}{l|l|l}
$21 \%$ & $17 \%$ & $63 \%$
\end{tabular}

3.2 Quality of the involvement of all students

\section{$13 \%$} $25 \%$

3.3 Frequency of formative assessment

\section{$29 \%$}

$4 \% \quad 67 \%$

3.6 Quality of the implementation of safe and appropriate strategies
$13 \%$
$50 \%$
$38 \%$

3.7 Frequency of student participation and engagement

$42 \%$

4.1 Quality of content (appropriate, relevant, etc.)

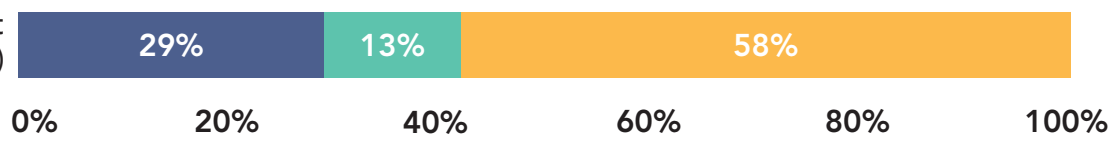

* Indicator Categories:

Indicators numbered 1=Classroom Environment, 2=Lesson Structure, 3=Implementation, and 4=Content. 
Video Findings. The overall findings from the video observations are positive with the majority of teachers showing positive changes in their practice. On average, participants saw positive growth on over $80 \%$ of the indicators (27 of the 34 ) in the study, which measured the overall quality of classroom instruction (see Chart 1 on page 20). Of the 27 indicators on which teachers demonstrated positive growth, more than half of the indicators with the greatest change were in two developmental areas, their command of the classroom environment and their lesson implementation. Examining specific indicators, the three indicators on which teachers demonstrated the biggest change measured the ways that the teacher engaged students. Sixty percent of the video participants improved anywhere between a quarter of a scale point to two and half points on these indicators. More than half of the 24 participants improved by between a half of a point to almost two points in their ratings for creating environments conducive for student engagement and collegial work. While not at the same magnitude, teachers also demonstrated positive change on all of the indicators for how they structured their lessons.

Female teachers tended to have greater changes in their ratings between their initial videos at start of the program and the videos from the end of the program, but it is important to note that female participants from the Cohort 3 agreed to participate in the full Reflective Classroom Initiative at a rate two times that of male participants. Sixteen female participants completed the Initiative compared to only 8 male participants.

When compared to the pre-program video observations, teachers demonstrated positive change in the frequency in which they used formative assessment in their lessons; however, the quality of the formative assessments and subsequent modifications within the lessons still needed improvement. These findings indicate that the teachers understand that formative assessment, a "big effects" practice, is important and are trying to use it in their classrooms. More time or likely, more training, is needed for them to implement it a way that is effective. 


\section{Self-reported Changes and Challenges from Surveys}

Table 4. Cohort 3 End-of-Program Survey Response Rates

\begin{tabular}{lcccc} 
& MATHEMATICS & SCIENCE & $\begin{array}{c}\text { ENGLISH } \\
\text { WRITING }\end{array}$ & $\begin{array}{c}\text { SCHOOL } \\
\text { LEADERS }\end{array}$ \\
\hline Number of surveys & 142 & 69 & 92 & 77 \\
Cohort Response Rate * & $98.6 \%$ & $57.5 \%$ & $82.1 \%$ & $55.8 \%$ \\
\hline
\end{tabular}

* Calculated as percent of Initial Participants.

Table 5. Cohort 3 Teacher Respondent

\begin{tabular}{|c|c|}
\hline & $\begin{array}{c}\text { PERCENT OF } \\
\text { RESPONDENTS }\end{array}$ \\
\hline Female & $62.0 \%$ \\
\hline \multicolumn{2}{|l|}{ HIGHEST DEGREE } \\
\hline High School & $.0 \%$ \\
\hline Diploma & $7.9 \%$ \\
\hline Bachelors & $58.4 \%$ \\
\hline High Diploma & $22.1 \%$ \\
\hline Masters & $8.3 \%$ \\
\hline Doctorate & $0.3 \%$ \\
\hline \multicolumn{2}{|l|}{ GRADES TAUGHT } \\
\hline 12th & $17.8 \%$ \\
\hline 11th & $18.5 \%$ \\
\hline 10th & $24.1 \%$ \\
\hline 9th & $23.1 \%$ \\
\hline 8th & $15.5 \%$ \\
\hline 7th & $12.2 \%$ \\
\hline 6th & $12.9 \%$ \\
\hline 5th & $11.6 \%$ \\
\hline 4th & $8.6 \%$ \\
\hline $1 s t-3 r d$ & $32.0 \%$ \\
\hline
\end{tabular}

Table 6. Cohort 3

Leader Respondent Background

\begin{tabular}{lc} 
& $\begin{array}{c}\text { PERCENT OF } \\
\text { RESPONDENTS }\end{array}$ \\
\hline Female & $33.8 \%$ \\
Previously a Teacher & $87.0 \%$ \\
HIGHEST DEGREE & \\
High School & \\
Diploma & \\
Bachelors & $2.6 \%$ \\
High Diploma & $2.6 \%$ \\
Masters & $41.6 \%$ \\
Doctorate & $36.4 \%$ \\
\end{tabular}

Source: Cohort 3 End-of-Program Leadership Survey 
Cohort 3 participants were surveyed ${ }^{3}$ when they started the program and toward the end of the program. The survey included items about teacher and school leader background characteristics, use of various instructional practices and participation in communities of practice, and school context. Survey items were drawn from CPRE surveys that were conducted in prior years, as well as other resources, including items developed by the Bay Area School Reform Collaborative (2002) teacher survey, Consortium on Chicago School Research (2001) teacher survey. There were challenges with the administration of the end-of-program survey. Participants were assigned individual unique IDs when they completed the pre-program survey; however, these IDs were not used in the administration of the end-of-program survey limiting the researchers' ability to link participants responses across the two surveys. For this reason, the majority of the survey analysis will focus on participants' responses as they completed the Project. Response rates for the Cohort 3 End-of-Program Surveys participants are displayed in Table 4 on page 22, and background of respondents are displayed in Table 5 and Table 6 on page 22 .

Response rates varied across the networks with the Math Network having the highest number of survey participants and school leaders having the lowest rate of response for Cohort 3. Response rates for the Science Network were also lower than preferred. The surveys were administered in the workshops toward the end of the program when attendance was lower. The surveys were also made available online, but not all of the teachers have access to the Internet making the workshop setting the only way for these teachers to access the survey.

Given the variation in participation, the results of these surveys should be interpreted with some caution. Specifically, it is possible, but unlikely, that participants who chose to complete the surveys are also those participants who are particularly engaged in the program, so the findings regarding change and frequency of use of instructional practices may be higher than the total population of participants as a whole. While the researcher team collected program completion survey data from Cohort 2 participants, an in-depth analysis is not included in this report since participation rates were below 50\% for multiple networks in this cohort.

3 The End-of-Program surveys for each Cohort 3 Network can be found at http://www.cpre.org/jordan-report 
Teacher Findings. The findings indicate that the improvement in classroom practices among the video participants was similar to the changes reported by their peers in Cohort 3 on the surveys. The majority of teachers in Cohort 3, across the networks, reported making a change in how often they used student collaboration and engagement in the classroom, the two areas in which the largest positive changes were observed in the video study. Nearly all of the science teachers (91\%) responded that they had increased how often they encouraged student discussion in class and $86 \%$ of both English writing and math teachers noted the same changes. More than $80 \%$ of the math and English writing teachers reported increases in their use of mixed groups or pairs to allow students at different levels to support each other. Over 70\% of English writing teachers also reported positive changes in this type of student collaboration.

Overall, the majority of the survey participants across the networks noted positive changes in their practice. On average, more than $80 \%$ of the surveyed teachers said that their was an increase in the amount of time for student reflection on their learning and the processes of the lesson, teacher use of questioning to assess learning and adjust their lessons, as well as their use of more student centered practices.

Challenges. Similar to the shared strengths and noticed changes in practice from the video study, the challenges reported by the video participants were also challenges for the teachers surveyed. Teachers' content knowledge was the area in which teachers demonstrated the least change between the pre-program videos and the videotaping toward the end of the program. This finding is not surprising since school leaders, support staff, workshop team members and even teachers themselves noted that content knowledge could be a weak area for some teachers. More than 60\% of English and math teachers surveyed cited their knowledge of their content area as a limiting factor for them in the classroom. Slightly fewer science teachers cited this reason, but still almost half noted it as a challenge. Almost $90 \%$ of school leaders sited teachers' knowledge of their content area as a limiting factor. While content knowledge was not a major focus of the program, increased understanding of the big ideas in the curriculum was expected to be a by-product of participation. The supports and workshop sessions tended to focus on the "big effects" practices and used the critical content as a medium to demonstrate how the practices could be applied to the subject. Additional support and a potential knowledge-building component in specific content areas may be a necessary addition for future programs with similar teachers. 
Time for collaboration with one's colleagues was a major challenge for Cohort 3 teachers across the networks, but teachers appear to be meeting more frequently than when they started the program. Fewer teachers reported "never" meeting with colleagues to discuss their instruction. The percent of teachers surveyed who reported "never" meeting with their peers to discuss content specific instruction decreased by an average of $15 \%$ for math and science respondents but only $2 \%$ for English teachers. This change indicates that more teachers were meeting with colleagues more frequently. More teachers also reported meeting on a daily or weekly basis, with the exception of English/Writing teachers. The percentage of science teachers reporting collaborating regularly more than doubled going from $22 \%$ to $54 \%$, math and English/writing teachers reported mixed changes. When considering the amount of time set aside for the meetings, roughly $60 \%$ to $70 \%$ of all surveyed teachers said that they were only able to meet for a few minutes or about a half an hour whenever they did meet. These reports are only marginally different from the amount of time that teachers reported having when they began the Network program meaning that, while teachers are able to collaborate more often, the amount time spent in these meetings is still limited.

Although more teachers reported meeting daily or weekly with colleagues who teach the same subjects, the goal is for a large majority if not all teachers to meet at least on a weekly basis. With the exception of the science network, which had slightly more than half of teachers collaborating regularly, only about a third of teachers are meeting either daily or weekly. That means that $70 \%$ of those surveyed are meeting only a few times a semester if at all.

Leadership findings. On average, $80 \%$ of the school leaders who responded to the surveys noticed changes in teachers practices related to the goals of the Project as well as changes in their own practice and the level of encouragement given to teachers who were trying to implement the program practices. Most of the school leaders said that there was an increase in the number of times that supervisors and 
principals observed teachers. The majority of principals and supervisors also saw a notable change in the types of questions that participating teachers were employing in the classroom, noting that they were higher level questions and that teachers were probing for student understanding of content. School leaders also noted increases in their level of encouragement of student discussion and in their observation of teachers' use of student discussion in lessons, 79\% and 87\% respectively. Eighty-five percent of the leadership participants noticed a change in the level of encouragement they were giving to teachers for the use of group work in the classroom. It is worth noting that less than two-thirds of principals and supervisors noticed an increase in "the amount of time that teachers have during the regular school week to work with colleagues on curriculum and teaching methods." While 64\% still includes the majority of the respondents, it is much lower than the change reported in the other areas explored. Interestingly, it is reflective of the challenges reported, both through survey responses and anecdotally, by teachers, school leaders, and workshop team members. Each group reported that finding time to collaborate with peers was an ongoing challenge for teachers. More than 70\% of school leaders surveyed cited the lack of time available for planning and lesson collaboration as a limiting factor for teachers.

Concerns about teacher's content knowledge and instructional abilities also were expressed by the Cohort 3 principals and supervisors who participated in the end-of-program survey. About half of the school leaders lacked confidence in their teachers' ability to help struggling students become proficient. Even though the majority noticed an increase in teachers' use of higher lever questions, almost 60\% of the leadership respondent still questioned teachers' ability to use the questions to promote student learning. Almost half of the principals and supervisors also lacked confidence in teachers' ability to identify student misconceptions and address the conceptual errors. 


\section{Similar Findings from Cohort 1 and Cohort 2}

The initial documentation report submitted in 2011 described and summarized the first-year implementation activities, including the professional development program, content, and participation rates. The findings suggested that there were high participation rates in both workshops and network meetings, and moderate rates of attrition, with slightly higher rates of attrition in the writing network than in the other networks attributed largely to the lack of focus on writing in the Jordanian curriculum as well as the time demands associated with the use of the writing workshop. Workshop team leaders worked with the ministry to make it clear to English writing teachers that it was acceptable to use the workshop practices in their classrooms. The workshop team noted that this support helped to some degree with teacher buy-in and attrition. The first-year report also examined participants' response to the Project, including satisfaction with the program as well as attitudes toward and self-reports of the use of the strategies introduced and supported through the professional development program. Overall, teacher and principal views of the workshop were positive regarding the organizational aspects, leadership of the workshops, and content of the workshops. Participants reported that much of it was new material that was relevant, and that it was useful in their classroom.

\section{Building Capacity within QRTA}

When the Partnership began the Project, one intention was to build the organizational capacity of the QRTA so that it could provide high quality, effective professional development. Two particular aspects of building that capacity were developing staff and establishing quality assurance mechanisms. Developing QRTA staff would enable them to lead and support instructional improvement in participating schools. This effort included expanding QRTA's staff through a targeted recruitment strategy that sought educators with appropriate content knowledge, pedagogical content knowledge, and familiarity with Jordanian public schools, and an understanding of the core instructional concepts and practices advanced by the Partnership. 
Since 2009, the staff contributing to the Project has almost tripled. In 2009, there were only 9 team members with the majority being at the management level. Today, there are 25 team members supporting the project including workshop team leaders and facilitators as well as a researcher leading future measurement and evaluation of the Project. CPRE team members used an apprenticeship model to prepare current QRTA staff to design and lead professional development. The training and transfer was gradual with QRTA staff taking on greater responsibility for the workshops with Cohort 3 (See Table 7 below). After each workshop, participants were asked to provide anonymous survey feedback. This feedback was used to get educators' perspectives on what was presented and to adjust future workshops if necessary. This feedback was also used to track the quality of the transition and continuity of the content presented. The feedback data were analyzed from all three cohorts to assess whether changes in participants' feedback occurred over time as QRTA workshop leaders took on a greater role in leading the workshops. The feedback on the workshops' organization, content presented, and usefulness remained pretty constant, on average, across the cohorts (See Table 8 on page 29) indicating that QRTA workshop team leaders were delivering professional development that was on par with that of the CPRE workshop leaders.

Table 7. Transitioning of Responsibilities to QRTA Staff Developers

\begin{tabular}{|c|c|c|c|}
\hline & COHORT 1 NETWORKS & COHORT 2 NETWORKS & COHORT 3 NETWORKS \\
\hline \multirow[t]{3}{*}{ QRTA Staff Role } & Support Role & Co-deliver & Serve as \\
\hline & in Workshops & Workshop & Team Leaders \\
\hline & and Planning & Sessions & and Members \\
\hline \multirow[t]{2}{*}{ TC/CU Partner Role } & Lead in Content & Co-deliver & Advise as \\
\hline & and Delivery & Workshop Sessions & QRTA Leads \\
\hline
\end{tabular}

Source: Growing School Networks for Instructional Improvement in Jordan, 2009-2010, 2011. 
Table 8. Average Teacher Views on the Organization and Facilitation of Network Workshops: November 2010-September 2014

\begin{tabular}{|c|c|c|c|c|c|c|c|c|c|}
\hline \multirow[b]{2}{*}{ Feedback Prompts } & \multicolumn{3}{|c|}{$\begin{array}{l}\text { MATHEMATICS } \\
\text { NETWORK }\end{array}$} & \multicolumn{3}{|c|}{$\begin{array}{l}\text { SCIENCE } \\
\text { NETWORK }\end{array}$} & \multicolumn{3}{|c|}{$\begin{array}{l}\text { ENGLISH WRITING } \\
\text { NETWORK }\end{array}$} \\
\hline & $\begin{array}{c}\text { Cohort } \\
1\end{array}$ & $\begin{array}{l}\text { Cohort } \\
2\end{array}$ & $\begin{array}{l}\text { Cohort } \\
3\end{array}$ & $\begin{array}{c}\text { Cohort } \\
1\end{array}$ & $\begin{array}{l}\text { Cohort } \\
2\end{array}$ & $\begin{array}{c}\text { Cohort } \\
3\end{array}$ & $\begin{array}{c}\text { Cohort } \\
1\end{array}$ & $\begin{array}{l}\text { Cohort } \\
2\end{array}$ & $\begin{array}{l}\text { Cohort } \\
\quad 3\end{array}$ \\
\hline $\begin{array}{l}\text { "The workshop was } \\
\text { well-organized." }\end{array}$ & $98.3 \%$ & $95.7 \%$ & $95.7 \%$ & $99.0 \%$ & $96.6 \%$ & $98.3 \%$ & $100.0 \%$ & $98.7 \%$ & $92.9 \%$ \\
\hline $\begin{array}{l}\text { "Time was used } \\
\text { efficiently in the } \\
\text { workshop." }\end{array}$ & $92.5 \%$ & $96.8 \%$ & $96.8 \%$ & $93.4 \%$ & $93.5 \%$ & - & - & - & - \\
\hline $\begin{array}{l}\text { "The leaders of this } \\
\text { workshop were } \\
\text { knowledgeable about } \\
\text { [my content area] } \\
\text { math/science/writing." }\end{array}$ & $98.2 \%$ & $98.2 \%$ & $98.2 \%$ & $98.6 \%$ & $94.6 \%$ & $99.5 \%$ & $100.0 \%$ & $98.0 \%$ & $95.2 \%$ \\
\hline $\begin{array}{l}\text { "What I gained from } \\
\text { this workshop made } \\
\text { it worth my time." }\end{array}$ & $92.1 \%$ & $95.7 \%$ & $95.7 \%$ & $95.9 \%$ & $93.1 \%$ & $93.6 \%$ & $100.0 \%$ & $93.3 \%$ & $91.0 \%$ \\
\hline
\end{tabular}

Source: QRTA Workshop Feedback November 2010 to September 2012

As previously noted, workshop attendance varied throughout each cohort and network (See Table 1 on page 12). Some workshops had greater attendance than others. Workshops with lower attendance meant that fewer program participants were able to engage in that professional development opportunity and fewer were able to provide feedback on the experience. It is important to note that those who did attend the workshops did not always opt to complete the anonymous surveys, so the feedback on the workshops may not be representative of all those who attended (See Table 9 and Table 10 on page 30). 
Table 9. Cohort 2 Workshop Feedback Surveys Response Rates

\begin{tabular}{|c|c|c|c|}
\hline & $\begin{array}{l}\text { MATHEMATICS } \\
\text { NETWORK }\end{array}$ & $\begin{array}{l}\text { SCIENCE } \\
\text { NETWORK }\end{array}$ & $\begin{array}{l}\text { ENGLISH WRITING } \\
\text { NETWORK }\end{array}$ \\
\hline \multicolumn{4}{|c|}{ Workshop Feedback Sources } \\
\hline Number of Workshops & 8 & 8 & 9 \\
\hline $\begin{array}{l}\text { Range in the Number of } \\
\text { Teachers in Attendance }\end{array}$ & $79.1 \%-95.1 \%$ & $60.3 \%-94.3 \%$ & $50.9 \%-87.0 \%$ \\
\hline $\begin{array}{l}\text { Range in the Number of } \\
\text { Teachers Who Chose } \\
\text { to Provide Feedback }\end{array}$ & $57.3 \%-71.3 \%$ & $28.2 \%-79.5 \%$ & $23.4 \%-55.5 \%$ \\
\hline
\end{tabular}

Source: QRTA Workshop Feedback April 2012 to September 2014

Table 10. Cohort 3 Workshop Feedback Surveys Response Rates

\begin{tabular}{|c|c|c|c|}
\hline & $\begin{array}{l}\text { MATHEMATICS } \\
\text { NETWORK }\end{array}$ & $\begin{array}{l}\text { SCIENCE } \\
\text { NETWORK }\end{array}$ & $\begin{array}{c}\text { ENGLISH WRITING } \\
\text { NETWORK }\end{array}$ \\
\hline \multicolumn{4}{|c|}{ Workshop Feedback Sources } \\
\hline Number of Workshops & 6 & 8 & 7 \\
\hline $\begin{array}{l}\text { Range in the Number of } \\
\text { Teachers in Attendance }\end{array}$ & $61.2 \%-90.3 \%$ & $49.5 \%-93.0 \%$ & $50.6 \%-86.1 \%$ \\
\hline $\begin{array}{l}\text { Range in the Number of } \\
\text { Teachers Who Chose } \\
\text { to Provide Feedback }\end{array}$ & $41.8 \%-78.9 \%$ & $49.5 \%-90.8 \%$ & $50.6 \%-86.1 \%$ \\
\hline
\end{tabular}

Source: QRTA Workshop Feedback April 2012 to September 2014 


\section{Sustainability}

Building the capacity of QRTA staff was a part of a larger goal for the Project, ensuring that the program and its practices were sustainable within the schools. Part of ensuring sustainability is making sure that required supports for implementation are in place. Following the first year of the project, on-site support at schools was provided somewhat unevenly by QRTA staff. On-site support for Cohort 1 teachers averaged close to two visits per year. Over the second cohort's first two years of participation, schools were visited an average of two times in the mathematics network, once or twice in the science network (a mean of 1.4 visits per school) and once in the English writing network with Cohort 3 visits following a similar pattern. The long travel distance between English Writing Cohort 2 schools in Aqaba as well as among the Cohort 3 schools in Mafraq, Irbid, Jarash and Ajloun and the QRTA offices in Amman likely contributed to the lower number of on-site support visits for those networks. Nonetheless, across all Networks, the goal of providing 12 hours of on-site support for each school annually (approximately three school visits per year) was not met. QRTA leadership and staff also provided limited, if any, on-site support for principals through school visits. Geography proved to be a challenge for the first three cohorts and could impede the Project from sustaining reforms within schools beyond the workshops and even beyond the program as participants were not fully supported as planned while they had access to the Project. The QRTA staff are aware of the importance of on-site support and are making efforts to meet participants needs.

The teacher meetings are another component of the Project that support participants. The goal is for each cohort to hold four Network meetings per year, which initially was only partially met for Cohort 1 since only the Science and English Writing Networks had four or more meetings. A similar trend continued with Cohort 2 and 3 where the English writing network held fewer than four teacher meetings, but both the Science and Math Networks held four or more teacher meetings. The increase in meetings held, with some networks holding more than four, suggest that the QRTA staff were able to address some of the obstacles to implementing frequent network meetings making it more likely that the practices of the Project were implemented by the school communities. 
Cohorts 4 and 5. While the CPRE team has not had a major role in working with the additional cohorts, they are aware that QRTA began work with a fourth and fifth cohorts. Adding these cohorts to the project means that more public school teachers in Jordan will have access to the supports and practices emphasized in the Project. Increasing educators' exposure to the Project increases the number of educators who have had extensive program training and will allow for more collaboration with other participants from previous cohorts further expanding the program network. Additionally, these participants can serve as leaders within their schools sharing their knowledge and practice with colleagues and helping to create communities of practice. A development that program teams already have seen happen within the other cohorts where teachers and school leaders report that they are sharing their knowledge with the peers and encouraging them to use the practices. More data on how the instructional improvement efforts are sustained within schools that participated in the Project will likely come from additional follow-up with participants from prior Cohorts now that they have completed the program. 


\section{LESSONS LEARNED}

Surveys and Data. The end-of-program surveys were administered to all participants, regardless of whether they completed the program. Researchers at QRTA wanted to include all participants since it was possible that they may have benefited from the program even though they did not complete all of the program components. While having these data may provide some insight, it is possible that the program had a different impact on participants who only partially engaged in the program when compared to their peers who were able to fully engage in all aspects of the program until its completion. Future evaluations should attempt to capture the experience of partial participants, but solicit their perspective separate from participants who complete the program.

The effectiveness of a survey is largely dependent on the researcher's ability to use language to convey the ideas to the participant. In the case of the Project, the surveys were created in English and then translated to Arabic. This process meant that, at times, the nuances of the words chosen in English got lost or did not quite convey the same ideas once translated. This challenge was one that was noticed earlier in the project so individuals who spoke both languages were brought in to help better convey these nuances in future surveys. Though it still was not perfect, it did improve the overall quality and understand of what was being measured.

In general, data collection presented challenges especially since much of the initial responsibility was placed on QRTA, which was a newer and growing organization at the beginning of the project. As a result, little baseline data were collected from the first two cohorts. It is possible that greater data collection could have taken place with more oversight from CPRE researchers. It might have also been beneficial for CPRE to manage the initial data collection since it was the more experienced organization. Then, the process could have been transitioned to the QRTA researchers much in the way that the workshop facilitation was transitioned.

Capacity Building. QRTA is a relatively new organization and has great aspirations for the work they can do as an organization. In an effort to realize some of its goals and obtain additional funding to sustain the organization, staff sometimes were charged with multiple tasks related to more than one initiative, which often divided their attention. There was never any question about the QRTA team members' dedication to the project or their belief in the work, but, at times, the needs of other initiatives left team members with less time for the Network Project. 
The unfortunate consequence was that some components, like site visits, were not fully implemented in the manner intended. When engaging in similar work in the future, it will be important to focus on not only building capacity in the form of additional staff members but also on ensuring that those gaining the knowledge and expertise needed to lead the program are able to devote the needed time to the project so that they are able to fully engage in that work.

Language Barriers And Gender Considerations. The CPRE trainers' lack of proficiency in Arabic has posed one of the more significant challenges in implementing the program. Providing feedback when Jordanian trainers were presenting was often difficult because concurrent word-for-word translations do not usually allow time for nuanced interpretation, a challenge given the importance of specificity and language in determining levels of conceptual understanding. Determining whether to press participants about specificity or clarity during a discussion of a concept was challenging since CPRE trainers were not always able to identify whether the problem was in the translation, or if the problem was the actual participants' understanding. One important adjustment was continually refining the language used during training and in the training materials as concepts become clearer to the Jordanian trainers and their understanding deepened. Additionally, one of the benefits to having QRTA trainers take on more responsibility for training was that less time was spent during the trainings providing translation. The transitioning of the project to local education trainers enabled more in-depth discussion on the concepts and practices that the Project emphasizes.

Gender was another area where the Project had to be thoughtful. Workshop leaders as well as other program team members noted teachers' level of engagement and, at times, their professional knowledge varied. Female teachers tended to have stronger credentials and be more open to growing as a professional, on average. Their attendance and effort was greater than their male counterparts. There were exceptions with some male participants displaying all of these characteristics and very eagerly engaging in the program and, vice versa, there were female participants who were quite the opposite. Team members knew that there might be gender differences based on anecdotes about how different the all-female schools are from the all-male schools. Greater attention should be given to anticipating these differences and incorporating approaches to managing them for participants. 


\section{CONCLUSION}

Overall, the School Network Project has had a positive impact on both educators and the staff at the Queen Rania Teacher Academy.

1. Teachers are reporting that they are using the "highly effective" practices that were emphasized in the workshops. This increased use was also noticed in the video observations of the teachers who participated in the Reflective Classroom Initiative.

2. School leaders are seeing positive changes in teachers' efforts to engage students and assess their learning as well as changes in other areas.

3. School leaders also reported changes in their own practices noting that they were observing teachers more frequently and that they were more supportive of teachers using the "big effects" practices.

4. CPRE team members were able to support and train QRTA team members to lead the workshops and other initiatives related to the Project.

5. QRTA has grown as an organization and has almost three times as many staff members to support instructional support in the years to come.

Continuing to engage the program participants and support them in their schools is an on-going effort. Teachers emphasize a need for a stronger professional community that collaborates regularly. QRTA has acknowledged the challenges that the partnership faced during the first five years of implementation and is exploring ways to improve the program. Adapting to the needs of the participants was a critical part of the program and continuing to assess the needs of educators and how best to meet those needs likely will continue to be a key component to the program's success. 
The partnership between CPRE and QRTA formed through the facilitation of CUMERC with the goal of improving the quality of the public education system through the provision of high quality in-service training to current teachers. Through this partnership, three cohorts of teachers have spent extensive amounts of time deeply engaging in researched-based practices and taking this gained knowledge back to their schools and classrooms. As the Project continues to grow, the professional community of Jordanian public school teachers will expand and it is the hope of the partnership that this community of educators will be able to meet the needs of their students and prepare them for the competitive world that awaits them. 


\section{ACKNOWLEDGMENTS}

A special thank you to all of the CPRE staff, QRTA staff, and consultants from Teachers College who aided in the implementation and evaluation of the School Network Project. Thank you to CUMERC for their continued partnership. Thank you to all of the school leaders, teachers, and all of the educators who participated in the Project dedicating their time and effort. The success of the Project would not have been possible without you. 


\section{(1) Consortium for Policy Research in Education Teachers College - Columbia University 525 West 120th Street, Box 124 \\ New York, NY 10027 \\ cpre-tc@tc.columbia.edu}

